\title{
Quantitative Estimation of Sorafenib Tosylate Its Pure Form and in Its Tablet Formulation by RP-HPLC Method
}

\author{
R. Kalaichelvi ${ }^{1}$ and E. Jayachandran ${ }^{2}$ \\ ${ }^{1}$ Department of Pharmaceutical Analysis, K. C. Reddy Institute of Pharmaceutical Sciences, Jangamguntla Palem, \\ Medikonduru Mandal, Guntur 522 348, India \\ ${ }^{2}$ Department of Pharmaceutical Chemistry, S.C.S. College of Pharmacy, Devanagari District, Karnataka, Harapanahalli 583131, India
}

Correspondence should be addressed to R. Kalaichelvi; rkselvi123@rediffmail.com

Received 21 June 2012; Accepted 31 July 2012

Academic Editor: Tingyue Gu

Copyright (c) 2013 R. Kalaichelvi and E. Jayachandran. This is an open access article distributed under the Creative Commons Attribution License, which permits unrestricted use, distribution, and reproduction in any medium, provided the original work is properly cited.

A simple, accurate, specific reverse-phase, high-performance liquid chromatography method has been developed for the determination of sorafenib tosylate in its pure form and its tablets. In this method, sorafenib tosylate was eluted by isocratic mode using a Phenomenex Luna C18 column by a mobile phase composition of acetonitrile and water in the ratio of $82.5: 17.5$, v/v. The flow rate was $1.5 \mathrm{~mL} / \mathrm{min}$. The eluted drug was monitored at $265 \mathrm{~nm}$ and the method was found to be linear from 5 to $80 \mu \mathrm{g} / \mathrm{mL}$. The method was validated by linearity, precision, accuracy, LOD, and LOQ. The accuracy report denotes that there is not any interference of additives used in the formulation.

\section{Introduction}

Sorafenib tosylate is chemically 4 -(4-\{3-[4-chloro-3-(trifluoromethyl) phenyl ] ureido phenoxy)- $\mathrm{N}-2$-methylpyridine-2-carboxamide 4-methylbenzenesulfonate. The drug was approved for the treatment of primary kidney cancer and advanced primary liver cancer. Sorafenib tosylate was estimated by RP-HPLC in human serum $[1,2]$. It was estimated in bulk and in tablets by RP-HPLC [3], HPTLC [4], colorimetric estimation [5], and by UV method [6, 7]. The present work aims to develop a simple, precise, and accurate RP-HPLC method for the estimation of sorafenib tosylate in pure drug and in its tablet formulation.

\section{Experimental Methods}

Sorafenib tosylate pure drug was obtained as a gift sample from Natco pharma (Hyderabad, India). All the reagents used were HPLC grade.

2.1. Instrumentation. The HPLC experiment was carried out in a Shimadzu HPLC system equipped with Phenomenex
Luna C18, $5 \mu \mathrm{m}(4.6 \times 250 \mathrm{~mm})$ column, two LC-20AD pumps, SCL-10AVP system controller, Rheodyne injector with $50 \mu \mathrm{L}$ loop, and SPD-20A UV-visible detector, and LC Solution software was used. All the reagents used were HPLC grade. The mobile phase was a mixture of acetonitrile and water $(82.5: 17.5, \mathrm{v} / \mathrm{v})$ that was set at a flow rate of $1.5 \mathrm{~mL} / \mathrm{min}$.

2.2. Drug Stock Solution. Stock solution of sorafenib tosylate was prepared by dissolving accurately weighed $100 \mathrm{mg}$ of the pure drug in $100 \mathrm{~mL}$ of mobile phase (final concentration, $1 \mathrm{mg} / \mathrm{mL}$ ). The prepared stock solution was stored at $4^{\circ} \mathrm{C}$ and protected from light.

2.3. Calibration Curve. From the above stock solution, $10 \mathrm{~mL}$ was taken and diluted to $100 \mathrm{~mL}$ with mobile phase. Subsequent dilutions of this solution ranging from $5-80 \mu \mathrm{g} / \mathrm{mL}$ were made in $10 \mathrm{~mL}$ volumetric flasks. The solutions were filtered through $0.45 \mu \mathrm{m}$ membrane filters and then $50 \mu \mathrm{L}$ of filtrate was injected each time into the column at flow rate of $1.5 \mathrm{~mL} / \mathrm{min}$. Evaluation of the drug was performed with 
TABLE 1: Assay results and precision studies.

\begin{tabular}{|c|c|c|c|c|c|}
\hline \multirow{2}{*}{ Sample } & \multirow{2}{*}{ Labeled amount (mg/tablet) } & \multirow{2}{*}{ Amount found (mg/tablet) } & \multirow{2}{*}{ (\%) label claim ${ }^{\mathrm{a}} \pm$ S.D } & \multicolumn{2}{|c|}{ Precision $^{b}$} \\
\hline & & & & Inter-day & Intra-day \\
\hline Sorafenib tablets & 200 & 199.76 & $99.98 \pm 0.297$ & 0.5998 & 0.2975 \\
\hline
\end{tabular}

TABLE 2: Recovery study.

\begin{tabular}{|c|c|c|c|c|}
\hline Sample & Label claim (mg/tablet) & $\begin{array}{l}\text { Amount of drug } \\
\text { added }(\mu \mathrm{g} / \mathrm{mL})\end{array}$ & $\begin{array}{c}\text { Amount of drug } \\
\text { recovered }(\mu \mathrm{g} / \mathrm{mL})\end{array}$ & Percentage recovery $\pm \mathrm{SD}^{\mathrm{a}}$ \\
\hline \multirow{3}{*}{ Sorafenib tablets } & \multirow{3}{*}{200} & 32 & 32.08 & $100.23 \pm 0.070$ \\
\hline & & 40 & 39.92 & $99.81 \pm 0.236$ \\
\hline & & 48 & 47.98 & $99.95 \pm 0.058$ \\
\hline
\end{tabular}

Mean of six determinations.

UV detector at $265 \mathrm{~nm}$. Peak area was recorded for all peaks. A plot of peak area versus the respective concentration gives the calibration curve. The regression of drug concentration over the peak area was computed. Unknown samples were estimated by reference to this calibration curve.

2.4. Sample Preparation. Twenty tablets were weighed accurately and crushed to fine powder. From that, the amount of powder equivalent to $100 \mathrm{mg}$ of sorafenib tosylate was weighed accurately and transferred to a $100 \mathrm{~mL}$ volumetric flask. Mobile phase $(50 \mathrm{~mL})$ was added and the mixture was sonicated for $10 \mathrm{~min}$, for complete extraction of the drug, and the solution was diluted to volume with mobile phase. Then solution was centrifuged at $4000 \mathrm{rpm}$ for $10 \mathrm{~min}$, and the clear supernatant was collected and filtered through a $0.2 \mu \mathrm{m}$ membrane filter. From this solution $10 \mathrm{~mL}$ was taken and diluted to $100 \mathrm{~mL}$ with mobile phase, again $4 \mathrm{~mL}$ was diluted to $10 \mathrm{~mL}$ to get $40 \mu \mathrm{g} / \mathrm{mL}$ solution, of which $50 \mu \mathrm{L}$ was injected for HPLC analysis.

\section{Results and Discussion}

A typical chromatogram of sorafenib tosylate was shown in Figure 1. The retention time for sorafenib tosylate was $3.4 \mathrm{~min}$. Flow rate was fixed at $1.5 \mathrm{ml} / \mathrm{min}$, which gives tailing factor in the acceptable limit. The peak areas from such different concentrations of 5 to $80 \mu \mathrm{g} / \mathrm{mL}$ were calculated. A good linear relationship $\left(r^{2}=0.998\right)$ was observed between the concentration drug and the respective peak area. The regression curve was constructed by linear regression fitting. The intraday and interday variations of the method were determined, a low coefficient of variation was observed. This shows that the present HPLC method is highly precise. To ensure accuracy of the method, recovery studies were carried out mixing a known quantity of drug with preanalyzed sample and the contents were reanalyzed by the proposed method. The recovery was about $99.95 \%$ to $100.23 \%$ (Table 2 ), indicating the high accuracy of the proposed HPLC method. The drug content in tablets was quantified using the proposed analytical method and the results are shown in Table 1.

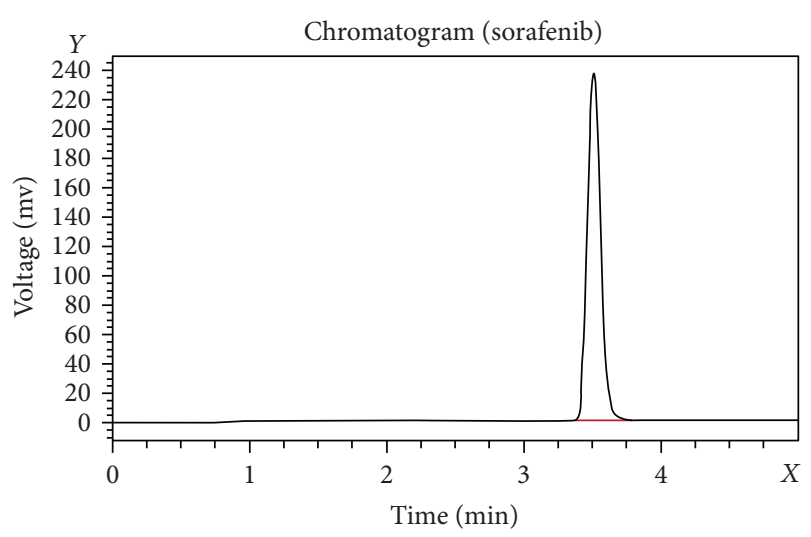

FIGURE 1: A typical chromatogram of sorafenib.

Chromatographic parameters such as peak asymmetry and capacity factor were found to be 1.03 and 0.921 , respectively. The limit of detection (LOD) and limit of quantification (LOQ) were found to be 0.133 and $0.403 \mu \mathrm{g} / \mathrm{mL}$, respectively. The precision of the method was calculated in terms of the relative standard deviation. Low values of relative standard deviation indicated high precision and accuracy of the proposed method.

\section{Conclusion}

The developed RP-HPLC method was simple, sensitive, precise, and accurate and hence can be used in routine for the determination of sorafenib tosylate in pure as well as in tablets.

\section{Conflict of Interests}

The authors declare that there is no conflict of interests.

\section{Acknowledgments}

The authors are very thankful to Natco Pharma, Hyderabad, for providing pure drug and are also thankful to management 
of K. C. Reddy Institute of pharmaceutical sciences, Guntur, for providing necessary facilities to carry out this work.

\section{References}

[1] B. Blanchet, B. Billemont, J. Cramard et al., "Validation of an HPLC-UV method for sorafenib determination in human plasma and application to cancer patients in routine clinical practice," Journal of Pharmaceutical and Biomedical Analysis, vol. 49, no. 4, pp. 1109-1114, 2009.

[2] W. J. Heinz, K. Kahle, A. Helle-Beyersdorf et al., "Highperformance liquid chromatographic method for the determination of sorafenib in human serum and peritoneal fluid," Cancer Chemotherapy and Pharmacology, vol. 68, no. 1, pp. 239-245, 2011.

[3] S. VenkataRao, G. Ramu, A. Biksham Babu, T. Neeharika, and C. Rambabu, "Determination of sorafenib in bulk and tablet formulation by a new validated reverse phase high performance liquid chromatography," Rasayan Journal of Chemistry, vol. 4, no. 2, pp. 477-480, 2011.

[4] P. A. Shivaji and T. G. Pramila, "HPTLC Determination of Sorafenib tosylate in bulk drug and pharmaceutical dosage form," International Research Journal of Pharmacy, vol. 3, no. 2, pp. 108-110, 2012.

[5] R. Kalaichelvi and E. Jayachandren, "Spectrophotometric estimation of sorafenib in pharmaceutical preparation," Journal of Pharmacy Research, vol. 4, no. 10, pp. 3707-3708, 2011.

[6] R. Kalaichelvi and E. Jayachandren, "UV spectrophotometric estimation of sorafenib in pure and tablet dosage form," Journal of Pharmacy Research, vol. 4, no. 10, pp. 3705-3706, 2011.

[7] A. S. Powar, T. Pramila, G. P. Senthilkumar, T. Tamizh Mani, P. S. Mahadik, and S. B. Jagtap, "UV spectrometric determination of sorafenib tosylate in bulk and pharmaceutical dosage form," American Journal of PharmTech Research, vol. 2, no. 1, pp. 356-361, 2012. 

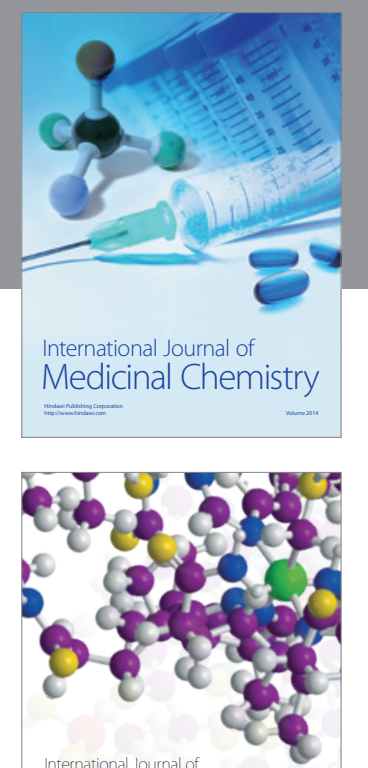

\section{Carbohydrate} Chemistry

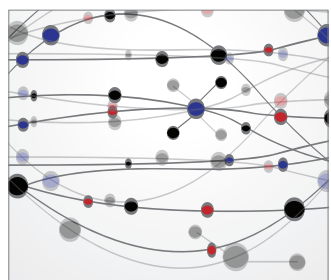

The Scientific World Journal
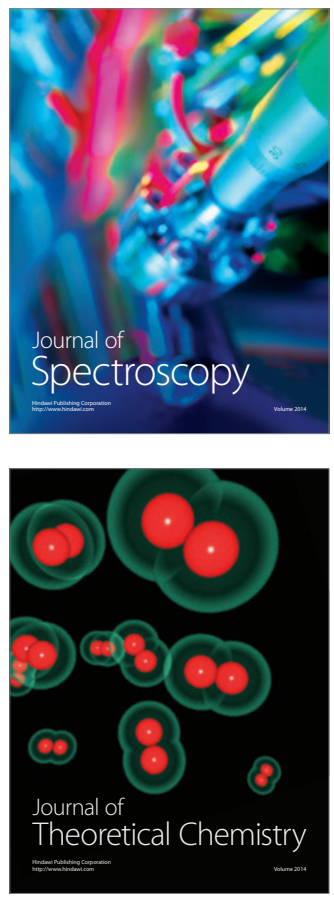
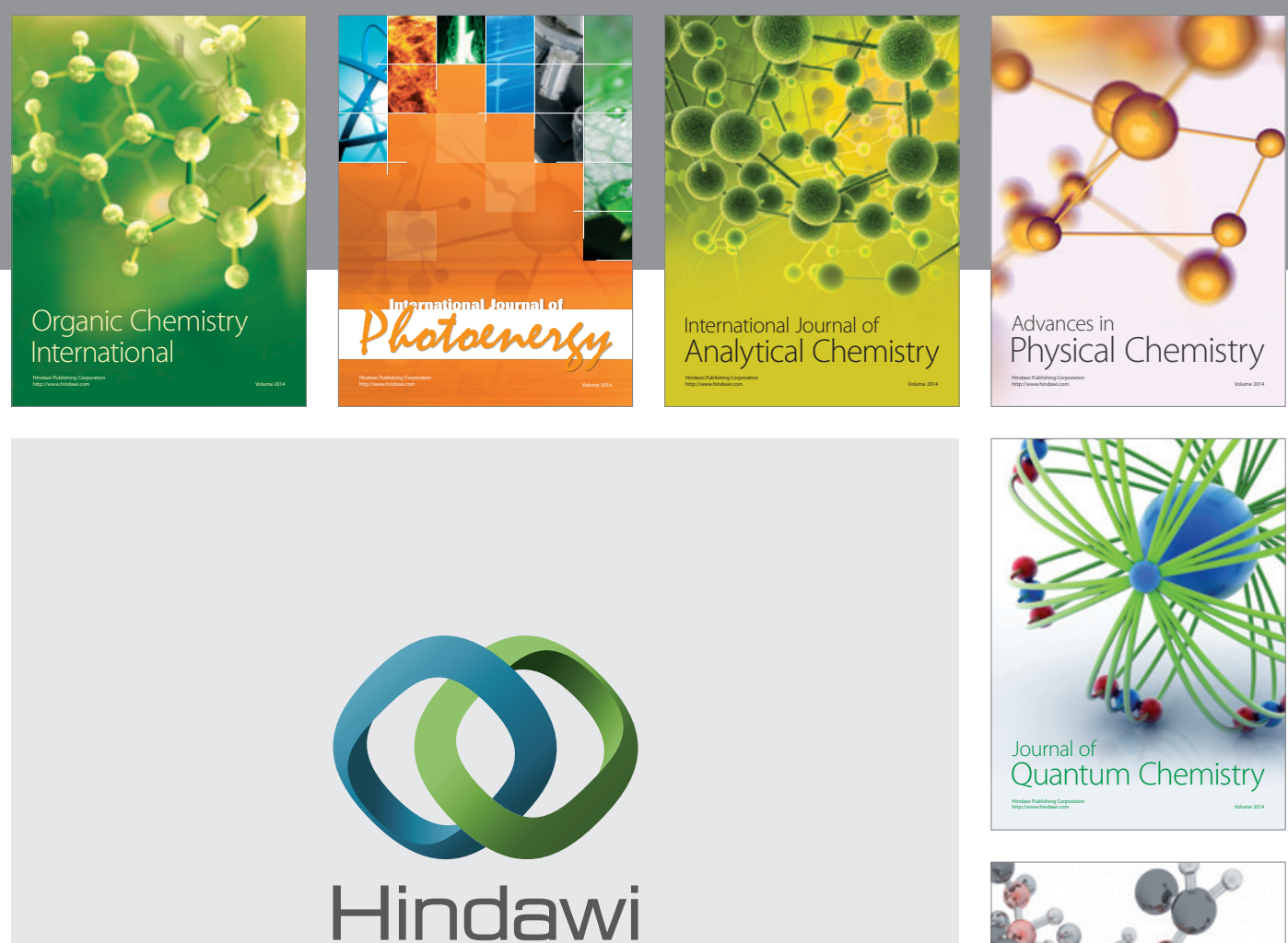

Submit your manuscripts at

http://www.hindawi.com

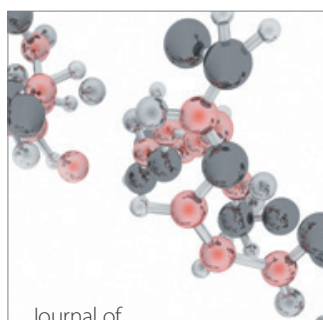

Analytical Methods

in Chemistry

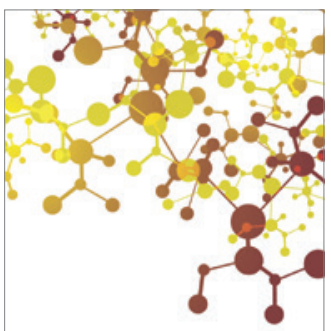

Journal of

Applied Chemistry

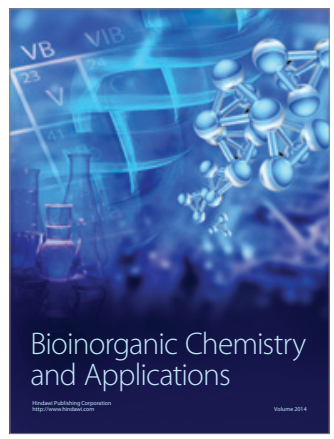

Inorganic Chemistry
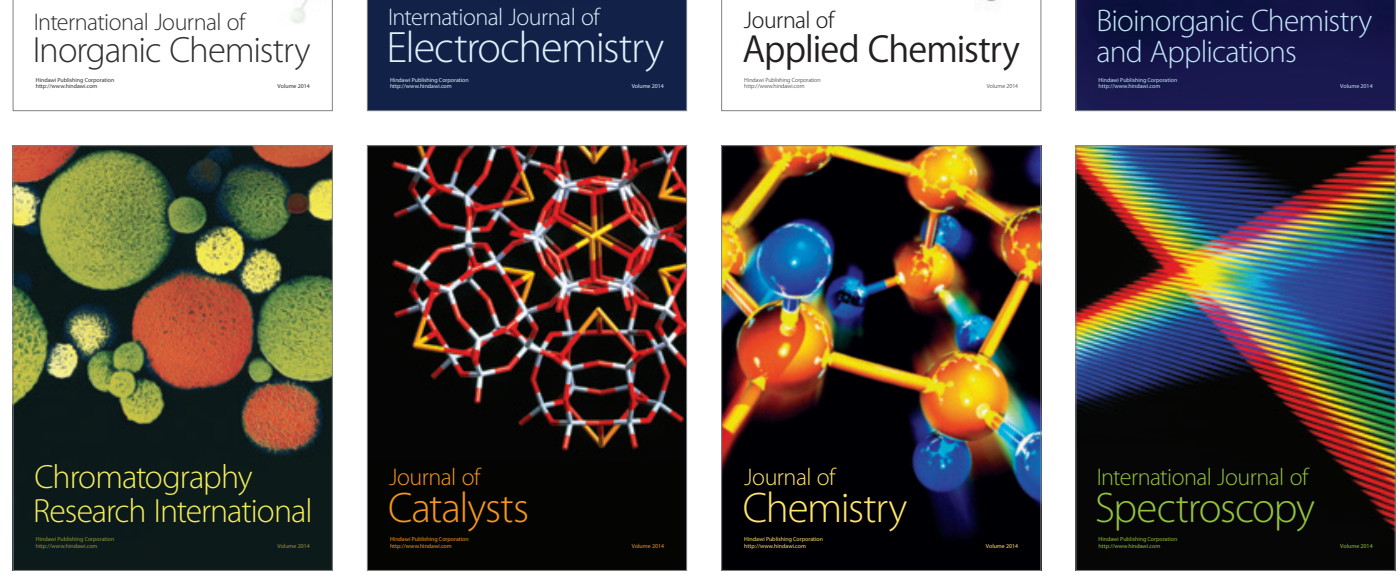